\title{
O GRANITO DA RAMADA, PORÇÃO OESTE DO ESCUDO SUL-RIO-GRANDENSE: GEOLOGIA, PETROLOGIA E GEOQUÍMICA
}

\author{
ROBERTO H. NAIME* \& LAURO V.S. NARDI**
}

\begin{abstract}
THE RAMADA GRANITE, WESTERN PART OF SUI-RIO-GRANDENSE SHIELD: GEOLOGY PETROLOGY AND GEOCHEMISTRY. The Ramada Granite is a post-OTogenic, epizonal intrusion, associated to alkaline magmatism which postdates die Brasiliano orogenesis. It is composed of aeno and monzogranites containing calcic-amphibofes (magnesium hornblende and feno-edenitic hornblende) and biotite, besides magnetite, ilmenite, titanite, zircon, allanite, and fluorite. Their textures vary from hypidiomorphic equigranular to porphyritic. As far as chemical composition is concerned they are not typically alcaline, although such affinity is pointed out by $\mathrm{FeO}(\operatorname{tyFeO}(\mathrm{t})+\mathrm{MgO}$ ratio higher than 0.9 , by high agpaitic index, and by $\mathrm{R} 1 \mathrm{R} 2$ plotting. The trace-element contents are not suggestive of alkaline affinity, except for rare earth element geochemistry. According to mineral chemistry data, mafic phases were crystallized under exceptionally high Poj conditions considering alkaline magmas. $\mathrm{Rb}$-Sr isotopic data indicate an age of $463 \pm 12.5 \mathrm{Ma}$ an initial ${ }^{87} \mathrm{Sr} /{ }^{86} \mathrm{Sr}$ ratio of 0.710 for these granitic rocks. The available data suggest the Ramada Granite is part of the alkaline Saibro Intrusive Suite, its origin is still controversial since the available data are consistent with partial melting of quartz-feklspathic high-grade metamorphic rocks or fiactionation of alkali feldspar plus dinopyroxene from trachytic liquids of mantle sources. Late hydrothermal activity may have modified the ${ }^{87} \mathrm{Sr} /{ }^{86} \mathrm{Sr}$ initial ratio and developed significant mineralization.
\end{abstract}

Keywords: Granites, A-type granites, alkaline granites, petrology, geochemistry, rare earth elements.

\begin{abstract}
RESUMO O Granito da Ramada é uma intrusão epizonal, pós-orogênica, associada ao magmatismo alcalino que sucede a orogênese brasiliana. Ele é constituído por sieno e monzogranitos com anfíbólio cálcico (magnésio homblenda e homblenda feno-edenítica) e biotita, além de magnetita, ihnenita, titanita, zircão, allanita e fluorita. Sua textura varia de equigranular hipidiomórfíca até porfirítica. Sua composição química não é tipicamente alcalina, sendo este caráter indicado pelas razões $\mathrm{FeO}(\mathrm{t}) / \mathrm{FeO}(\mathrm{t})+\mathrm{MgO}$ superiores a 0,9 , pelo elevado índice agpaítico e pela localização de suas amostras no diagrama R1R2. Quanto aos elementos traços, apenas as terras raras apresentam padrões indicativos de sua afinidade alcalina. Os dados de química mineral sugerem que a cristalização das fases máficas ocorreu sob condições excepcionalmente oxidantes para magmas alcalinos. Estudos isotopicos pelo método $\mathrm{Rb}-\mathrm{Sr}$ apontam para uma razão inicial de 0,710 e idade de $463112,5 \mathrm{Ma}$. Os dados interpretados sugerem que esta intrusão pode ser incluída na Suíte Intrusiva Saibro, sendo sua origem explicável tanto pela fusão parcial de rochas metamórfkas de alto grau quartzo-feldspáticas, como pelo fracionamento de feldspato alcalino e clinopiroxênio a partir de líquidos traquíticos de origem mantélica. A atuação de processos hidrotermais pode ter modificado a razão inicial ${ }^{87} \mathrm{Sr} /{ }^{86} \mathrm{Sr}$ e gerado mineralizações significativas.
\end{abstract}

Palavras-chaves: Granitos, granitos tipo A, granitos alcalinos, geoquímica, granitogênese, litoquunica, elementos terras raras.

INTRODUÇÃO A região oeste do Escudo Sul-rio-grandense mostra grande quantidade de corpos graníticos deformados e associados com eventos metamórficos, os quais provavelmente constituem granitos orogênicos, conforme sugestão de Martin \& Piwinskii (1972), além de diversos corpos granitóides sem deformação dúctil que, de acordo com a classificação desses autores, constituem corpos não-orogênicos ou pós-orogênicos, se forem considerados os dados regionais atualmente disponíveis.

Os granitóides orogênicos apresentam idades em torno de 700-800 Ma, conforme os dados apresentados por Soliani (1986). O magmatismo granítico assume afinidade shoshonítica por volta de $640 \mathrm{Ma}$, representada pelas rochas constituintes dos núcleos dos Complexos de Lavras do Sul e Santa Rita, que não apresentam evidência de deformação dúctil ou metamorfísmo regional. As rochas granítícas, com idades em torno de $550 \mathrm{Ma}$, mostram características típicas da série alcalina, sendo freqüentemente granitos bipersolvus metaluminosos a peralcalinos. Tal ambiente é muito similar, em seus traços gerais, aos descritos no Escudo Árabe (Harris 1985), na Córsega (Bonin 1982), no Sudão (Neary et al 1976) e em diversas outras regiões (Sylvester 1989 e Nardi \& Bonin 1991).

Muitos dados não se enquadram nesse esboço geral, como os referentes ao Complexo Granítico de Caçapava do Sul
(Nardi \& Bitencourt 1989), o que retrata a necessidade de dados radiométricos mais consistentes, relativos ao magmatismo brasiliano nesta região. Os dados radiométricos mais indicativos de $640 \mathrm{Ma}$ para o início do magmatismo são imprecisos, e é possível que novos dados diminuam o intervalo de tempo entre este e o magmatismo alcalino.

O Granito da Ramada constitui corpo de forma ovalada, com superfície aflorante de aproximadamente $65 \mathrm{~km}^{2}$, sem evidências de deformação dúctil ou metamorfismo regional, fazendo parte, possivelmente, dos granitos não-orogênicos já mencionados. Diversos autores já se referiram a esta intrusão - descrita originalmente por Leinz et al(1941) entre eles, Ribeiro et al (1966), Sartori (1978) e Moreira \& Marimon (1982).

Este trabalho tem como objetivo a apresentação e discussão de novos dados petrográficos, geoquímicos e radiométricos, em grande parte provenientes da dissertação de mestrado do primeiro autor (Naime 1987).

GEOLOGIA O Granito da Ramada aflora principalmente na forma de blocos e lajeados, não mostra deformação dúctil, registrando apenas os efeitos de fraturamentos, de direção predominante N60-70E e E-W. As rochas sedimentares encaixantes, pertencentes à Formação Maricá, são afetadas por metamorfismo de contato (Ribeiro 1983). A presença de 
margens resfriadas (Fig. 1), somada à geração de comubianitos (Naime 1987), bem como as características texturais deste corpo, indicam que o mesmo constitui intrusão epizonal. A presença de xenólitos do embasamento metamórfico, principalmente ao longo de alguns contatos (Fig. 1), é compatível com processo do tipo magmatic sloping, uma vez consideradas as evidências referidas anteriormente.

O contato sudoeste do granito dá-se em rochas vulcanoclásticas ácidas da denominada Formação Acampamento Velho, conformando o plateau da Ramada, onde as atitudes do acamamento das encaixantes são horizontalizadas, sugerindo um posicionamento passivo para a intrusão granítica, uma vez que se admite a simultaneidade do magmatismo riolítico com as manifestações intrusivas estudadas.

A porção norte do corpo granítico é dominada por tipos monzograníticos, contendo anfíbólio e principalmente biotita, com coloração avermelhada, texturas ineqüigranulares e eqüigranulares e granulação média a fina. Anfibólios são os máficos dominantes em algumas fácies finas, próximas à borda nordeste da intrusão. Tipos sienograníticos passam a predominar em direção à porção sul do corpo. Os sienogranitos são avermelhados, com granulação fina a média, textura variável, apresentando a biotita como fase máfica predominante.

Diques riolíticos freqüentemente intersectam a parte norte do Granito da Ramada. Em geral, estão muito cataclasados, contém anfibólio e biotita, e apresentam enclaves microdioríticos com dimensões menores do que 1 centímetro (Naime 1987).

$\mathrm{O}$ efeito do hidrotermalismo pode ser observado tanto na formação de veios de quartzo mineralizados com fases sulfe- tadas quanto pelo desenvolvimento de sericitização, carbonatação e outras fases secundárias, como clorita, epídoto e óxidos de ferro em diversas das amostras coletadas. Controladas principalmente por fraturas de direção E-W, desenvolvem-se zonas greisenizadas de alguns metros de espessura, com fluorita rósea e incolor.

PETROGRAFIA O Granito da Ramada mostra composição dominantemente monzogranítica em sua porção norte, gradando para termos sienograníticos na porção sul (Figs, 1 e 2 ). A coloração avermelhada é bastante característica das rochas estudadas, sendo devida provavelmente à oxidação hidrotermal e intempérica, provocando a mudança de coloração dos feldspatos.

Texturalmente, os granites estudados, de forma predominante, são eqüigramilares hipidiomórficos, com granulação média a fina. São observadas texturas ineqüigranulares e mesmo porfíríticas. O feldspato alcalino é pertítico, sendo altamente dominante o componente potássico. Em geral, o feldspato alcalino está muito turvo e seus grãos incluem plagioclásio e cristais idiomórficos de quartzo. O plagioclásio, geralmente oligoclásio, pode chegar a andesina em alguns monzogranitos. Apresenta-se freqüentemente zonado e por vezes circundado por albita. Nos sienogranitos, os plagioclásios mostram distribuição heterogênea, lembrando texturas glomeroporfiríticas. Na maior parte das vezes, os plagioclásios estão alterados, com formação de muscovita, epídoto e carbonates de origem hidrotermal. O anfibólio é virtualmente restrito às fácies monzograníticas, principalmente às de granulação fina. É dominantemente subédrico, corroído e de

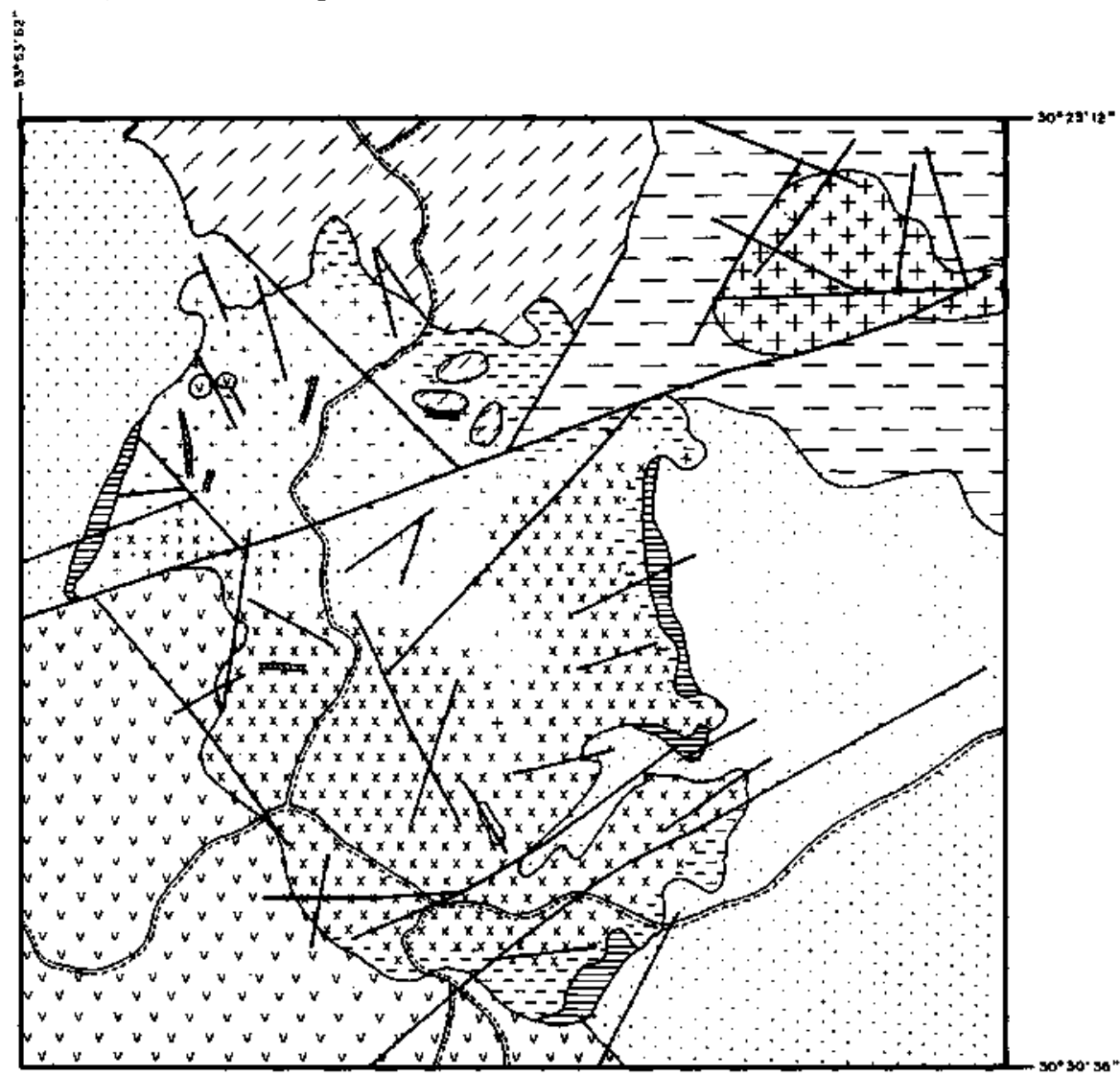

Legendo
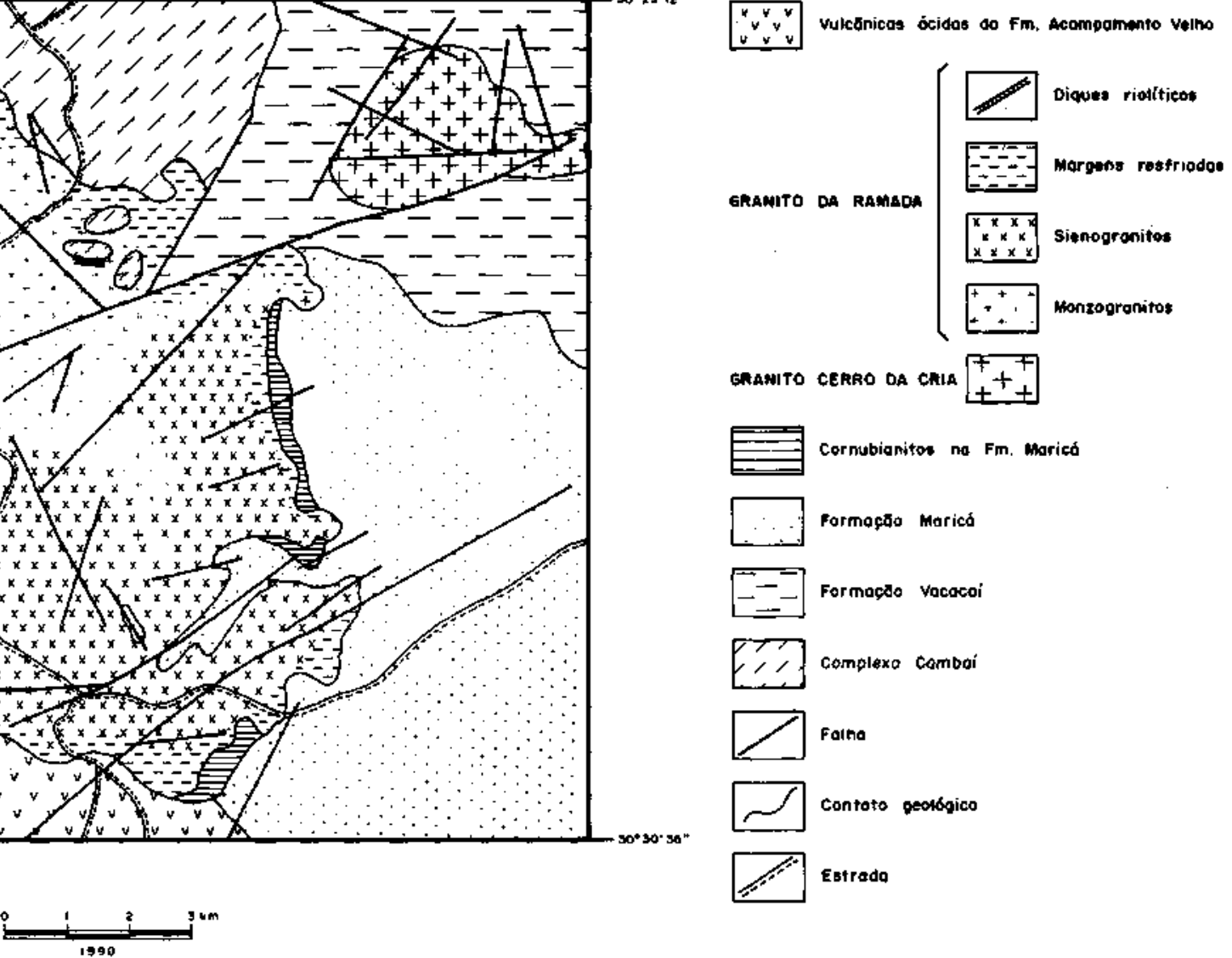

Figura 1 - Mapa geológico do Granito da Ramada (Naime 2987)

Figure l - Geologic map of the Ramada Granite (Naime 1987) 


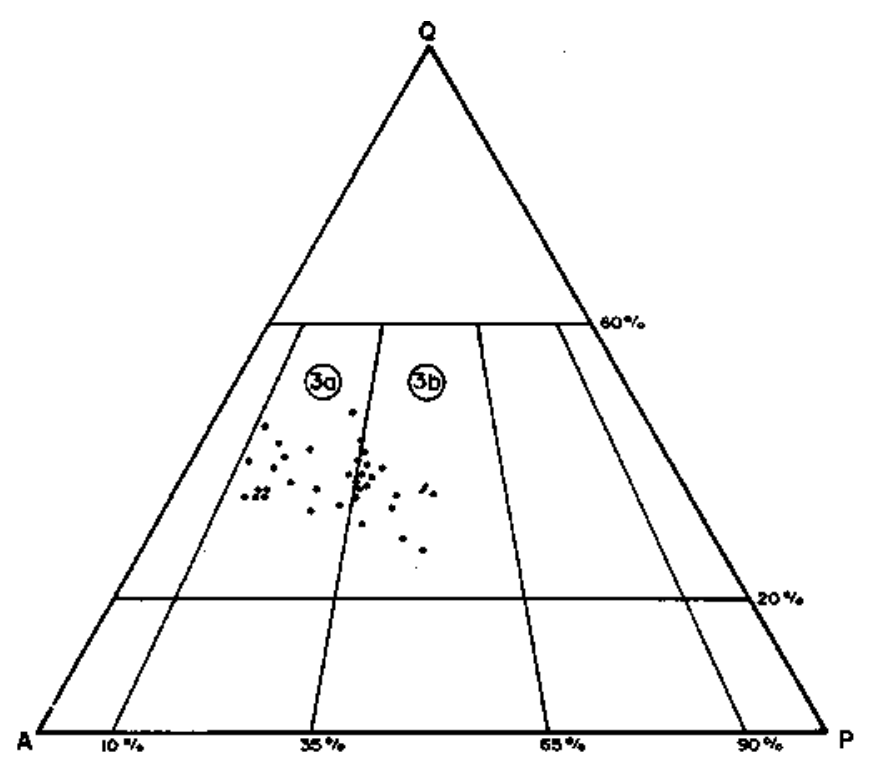

Figura 2 - Representação da composição modal de amostras representativas do Granito da Ramada

Figure 2 - Modal composition of representative Ramada Granite samples plotted in die QAP diagram

cristalização precoce. Seu pleocroísmo varia de verde a castanho-claro $(\mathrm{X})$, castanho-esverdeado $(\mathrm{Y})$ e verde a verdeazulado (Z); o ângulo $2 \mathrm{~V}$ é grande e o ângulo de extinção entre 12 e 15 graus. Optícamente, pode ser classificado como homblenda. A alteração mais comum desses anfibólios é para clorita e óxidos de ferro. A biotita é subédrica, com pleocroísmo variando de creme a castanho, nos tipos sienograníticos a coloração acentua-se até castanho-escuro e o hábito pode ser fibrorradiado além de lamelar. A alteração para clorita é freqüente.

Titanita, zircão em pequena quantidade e allanita, muitas vezes circundada por coroas de epídoto, são os minerais acessórios mais importantes. Magnetita, ilmenita e fluorita foram também identificados.

As relações texturais sugerem que a cristalização magmática foi iniciada com a formação de anfíbólio e plagioclásio, seguindo-se quartzo, biotita e feldspato alcalino. A presença de anfibólio subédrico ou euédrico, em equilíbrio com óxidos de ferro e titânio em fácies finas monzograníticas, atesta sua cristalização precoce. A ocorrência de mesopertita abundante (Ab/Or próxima de 1:1) em termos sienogranitos pode indicar cristalização hipersolvus, ao menos nos líquidos com baixo teor de cálcio.

GEOQUÍMICA As rochas graníticas que apresentam teores de $\mathrm{SiO}_{2}$ elevados e intervalos de variação restritos são de difícil enquadramento nas classificações baseadas em parâmetros químicos. A utilização destas pressupõe a existência de composições intermediárias, permitindo a definição de trends composicionais. É de ressaltar que, em sistemas ricos em sflica $\left(\mathrm{SiO}_{2}\right.$ superior a $\left.73 \%\right)$, o efeito de soma constante assume conseqüências ponderáveis e os próprios processos petrológicos e geoquímicos adquirem peculiaridades decorrentes da maximização do papel desempenhado por fatores como atividade de fluídos, saturação dos líquidos em elementos incompatíveis, polimerização e outros. Trabalhos recentes têm discutido tais fatores: Gwinn \& Hess (1989) reportam o efeito peralcalino em líquidos riolíticos, aumentando substancialmente a solubilidade dos cations de carga elevada, dificultando a cristalização de fases como zircão, ilmenita, magnetita etc; Nash \& Crecraft (1985) apresentaram dados de coeficientes de partição para líquidos riolíticos, compro- vando o aumento marcante de seus valores para grande parte dos elementos investigados. Por todas estas razões, a distinção dos termos altamente diferenciados das diversas séries magmáticas e dos produtos de fusão crustal torna-se freqüentemente inviável (Sylvester 1989) ou, por sua dificuldade, gera interpretações equivocadas.

O Granito da Ramada constitui, ao menos em parte, um sistema desse tipo, exigindo portanto, estudos mais acurado e fundamentados em análise crítica da metodologia utilizada no tratamento e interpretação dos dados.

A composição química, elementos maiores e alguns traços de 34 amostras dos monzo e sienogranitos do Granito da Ramada são mostrados na tabela 1 . As análises de elementos maiores e de $\mathrm{Zr}, \mathrm{Ba}, \mathrm{Sr}, \mathrm{Rb}, \mathrm{Pb}, \mathrm{Zn}$ e $\mathrm{Cu}$ foram realizadas por fluorescência de raios $\mathrm{X}$ e absorção atômica para os três últimos, no Laboratório de Geoquímica da UFRGS, sob a responsabilidade da prof ${ }^{\mathrm{a}}$ Dione A. Pintaúde. As demais análises, incluindo elementos terras raras, foram realizadas nos laboratórios da GEOSOL Ltda, sob responsabilidade do dr. Gáudio Vieira Dutra.

Os dados sobre a norma CEPW indicam que tanto os monzo como os sienogranitos estudados são metaluminosos. Este caráter é confirmado nos diagramas de Debon \& Lê Fort (1983), cuja aplicação torna-se prejudicada para outras considerações, uma vez que as amostras estudadas estão localizadas próximas às convergências dos trends cálcio-alcalino e alcalino. É possível constatar, nos mesmos diagramas, que as amostras do Granito da Ramada localizam-se nos campos dips adamelitos e dos granites com biotita ou biotita e anfibólio, ou ainda dos leucogranitóides.

Os teores de elementos maiores do Granito da Ramada foram comparados com os teores referidos por Ewart (1979) para associações riolíticas orogênicas típicas, destacando-se aquelas dos Andes, oeste dos EUA, e Japão. Constatou-se que, para rochas com o mesmo grau de diferenciação, os granites estudados possuem teores de $\mathrm{Na}_{2} \mathrm{O}+\mathrm{K}_{2} \mathrm{O}$ e razões $\left(\mathrm{Na}_{2} \mathrm{O}+\mathrm{K}_{2} \mathrm{O}\right) / \quad \mathrm{A}_{2} \mathrm{O}_{3}, \quad\left(\mathrm{Na}_{2} \mathrm{O}+\mathrm{K}_{2} \mathrm{O}\right) / \quad \mathrm{CaO}$ e $\mathrm{FeO}(\mathrm{t}) /$ $(\mathrm{FeO}(\mathrm{t})+\mathrm{MgO})$ mais elevados que os riolitos cálcio-alcalinos orogênicos. Tais parâmetros sugerem uma afinidade alcalina para os granites estudados, sendo a última razão listada superior a 0,9 , valor encontrado tipicamente nas rochas ácidas da série alcalina. O comportamento das amostras estudadas em diagramas envolvendo elementos maiores como o $\left(\mathrm{Na}_{2} \mathrm{O}+\mathrm{K}_{2} \mathrm{O}\right) \mathrm{X} \mathrm{FeO}(\mathrm{t}) \mathrm{X} \mathrm{MgO}$ (Fig. 3), ou o diagrama de Wright (1969) (Fig. 4), ou Rogers \& Greenberg (1981), confirmam o caráter alcalino.

Sobre a figura 5, é interessante ressaltar que os trends de diferenciação verificados para as amostras graníticas assemelham-se aos observados nas rochas vulcânicas orogênicas. São ainda notáveis as tendências de empobrecimento do AUOs com o aumento de $\mathrm{SiO}_{2}$ registrados na figura 5. A ocorrência de dois trends paralelizados de redução dos teores de $\mathrm{TiO}_{2} \mathrm{e}$ $\mathrm{P}_{2} \mathrm{O}_{5}$ mostram também empobrecimento em $\mathrm{CaO}$. A diversificação dos trends apresentados por estes três elementos pode resultar de processos localizados de fracionamento de minerais como titanita, apatita e, talvez, ilmenita. Os processos localizados de fracionamento têm sido reportados por diversos autores, principalmente em corpos graníticos muito diferenciados (Sultan et al. 1988).

Conforme enfatizado por Bonin (1988), a proporção de álcalis em relação à alumina é mais diagnostica das rochas da série alcalina que o aumento absoluto do teor de álcalis. Assim, o índice agpaítico ( $\mathrm{Na}+\mathrm{K} / \mathrm{Al}$ em átomo-grama) é maior do que 0,88 para a grande maioria das rochas da série alcalina, como observado também por Liegeois \& Black (1987). De acordo com esse critério, o Granito da Ramada apresenta afinidade alcalina, sendo o índice agpaítico das amostras estudadas maior do que 0,90 .

Ainda sobre os elementos maiores, as amostras do Granito da Ramada foram plotadas no diagrama R1R2 (De La Roche et 
Tabela 1-Resultado de análises químicas de amostras representativas do Granito da Ramada Table 1 - Chemical composition of Ramada Granite representative samples

\begin{tabular}{|c|c|c|c|c|c|c|c|c|c|c|c|c|c|c|c|c|c|}
\hline 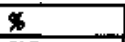 & M 4L & RM 11 & RM 100 & RM 112 & RM_133 & RM 146 & RM 147 & RM 150 & RM 151 & $\mathrm{RM} \mathrm{153}$ & RM 20 & RM 5 & RM 64 & RM 179 & RM 198 & RM 226 & RM 247 \\
\hline $\mathrm{SO}_{2}$ & 74,51 & 74,16 & 76,70 & 75,28 & 76,20 & 74,99 & 74,26 & 75,06 & 74,65 & 75,87 & 7,57 & 71,31 & 73,91 & 72,06 & 73,57 & 75,13 & $\overline{2,03}$ \\
\hline $\mathrm{HO}_{2}$ & 0.28 & 0,31 & 0,17 & 0,28 & 0,20 & 0.22 & 0,31 & 0,18 & 0,19 & 0,18 & 0,01 & 0,35 & 0,36 & 0,33 & 0.33 & 0.26 & 031 \\
\hline $\mathrm{Al}_{4} \mathrm{O}_{3}$ & 12,83 & 12,36 & 12,21 & 12,54 & 13,01 & 13,00 & 12,34 & 12,82 & 12,74 & 12,17 & 13,39 & 13,25 & 13,31 & 13,61 & 13,93 & 13,13 & 13,74 \\
\hline $\mathrm{Fr}_{2} \mathrm{O}_{3}$ & 0,08 & 0,07 & 0,07 & 0,10 & 0,00 & 0,17 & 0,07 & 0,01 & $\operatorname{ags}$ & 0,07 & 2,64 & 153 & $Q \overline{\alpha s}$ & 0,73 & 0,15 & 0,05 & 0,63 \\
\hline $\mathrm{E} \in \mathrm{O}$ & 1,03 & 1,70 & 1,70 & 1,13 & 1,27 & 1,34 & 153 & 1,82 & 1,32 & 1,16 & 0,01 & 1,39 & 247 & 1,49 & 1,86 & 0.94 & 219 \\
\hline Mno & 0,01 & 0,00 & 0,01 & 0,01 & 0,01 & 0,01 & 0,01 & 0,01 & 0,01 & 0,01 & 0,04 & 0,05 & 0,03 & 0,04 & 001 & 0,01 & 0,04 \\
\hline $\mathrm{Mag}$ & 0,01 & 0,04 & 0,02 & 0,01 & 0,01 & 0,02 & 0,01 & 0,01 & 0,01 & 0,01 & 0,09 & 0,20 & 0,04 & 0,0 & 0,03 & 0,01 & 0,07 \\
\hline $\mathrm{CHO}$ & 0,62 & 0,63 & 0,43 & 0,62 & 0,43 & 0,13 & 0,67 & 0,37 & 0,42 & 0,47 & 1,08 & 1,06 & 0,74 & 0,99 & 0,75 & 0,95 & 0,91 \\
\hline 50 & 3,97 & 4,11 & 3.84 & 3,91 & 4,23 & 4,23 & 390 & 4,11 & 437 & 4,73 & 4,23 & 4,09 & 417 & 4,08 & 3,76 & 4,75 & 4,57 \\
\hline Ko & 496 & 4,60 & 4,4 & 4,54 & $4, n$ & 4,75 & 4,73 & 4,88 & 4,70 & 4,67 & 4,48 & 4,45 & 4,70 & 4,73 & 485 & 4,45 & 457 \\
\hline FF (9000) & 0,57 & 0,71 & 0,72 & 0,85 & 0,45 & 0,56 & 0,90 & 0,50 & 050 & 0,4 & 1,14 & 2,23 & 0,72 & 0,71 & 0,3 & 0,45 & 0,61 \\
\hline $\mathrm{Fn}^{-}$ & 02 & 0,27 & 023 & 0,38 & 0,20 & 0,23 & 0,39 & 0,37 & 0,20 & 0,24 & 0,33 & $\overline{0,40}$ & $0, \overline{9}$ & 0,37 & 0,12 & 020 & 0,31 \\
\hline $\mathbf{P O} \mathrm{O}_{3}$ & 0,10 & 0,13 & 0,08 & 0,10 & 0,07 & 0,07 & 0.10 & 0,07 & 0,07 & 0,06 & 0,12 & 0,11 & 0.14 & 0,11 & 0,11 & 0,09 & 0,09 \\
\hline The & 99,17 & 9927 & 100,62 & 99,75 & 100.85 & $99, \overline{2}$ & 99,16 & 100,20 & 9927 & 9,59 & 100,10 & 100,42 & 10097 & 99,32 & 10030 & 100,42 & 100,07 \\
\hline B $(p, p)$ & 410 & 415 & 125 & 210 & 455 & 585 & 410 & 110 & 425 & 150 & 759 & $\mathbf{1 2 2 0}$ & 800 & 120 & 796 & 185 & 1135 \\
\hline $\mathbf{N}$ & nd & 20 & 20 & 20 & nd & nd & nd & nd & nd & Ind & 20 & nd & 20 & 20 & 20 & nd & 40 \\
\hline $\mathbf{L}=$ & nd & 5 & 5 & 5 & nd & in & $\overline{0}$ & nd & nd & ind & 39 & nd & 9 & 26 & 13 & nd & $\pi$ \\
\hline$s=$ & 30 & $<30$ & $<0$ & 80 & $\mathbf{5 0}$ & 40 & $\$ 30$ & $<30$ & 30 & 830 & 110 & 185 & 165 & 100 & 110 & 120 & 115 \\
\hline $\mathbf{R b} \quad \mathbf{A}$ & 170 & 160 & 165 & 189 & 160 & 170 & 140 & 150 & 140 & 145 & 150 & 135 & 150 & 149 & 150 & 100 & 105 \\
\hline $\mathbf{Y}$ & nd & Ind & 42 & 40 & $\mathrm{~m}$ & ind & d & ad & of & ind & 37 & nd & 27 & 32 & 14 & od & 27 \\
\hline $\mathbf{z r}=$ & 160 & 195 & 115 & 155 & 190 & 210 & 170 & 170 & 175 & 170 & 165 & 200 & 180 & 195 & 145 & 60 & 200 \\
\hline$z_{n}=$ & 5 & 49 & 75 & 40 & 55 & 50 & 40 & 55 & 40 & 100 & 80 & 65 & 4 & 85 & 50 & 70 & 50 \\
\hline 5 & RM 299 & RM 274 & RM 275 & RM 155 & RM 166 & RM 277 & PM 278 & RMn & RM 23 & RM 40 & RM 190 & RM 260 & RM 261 & RM 276 & $\overline{R M} 36$ & \begin{tabular}{|l|} 
RM 47 \\
\end{tabular} & RM 268 \\
\hline $\mathrm{SO}_{2}$ & 73,74 & $7, \overline{86}$ & 69,08 & 75,92 & 74,59 & 73,10 & $7 \overline{5,32}$ & 7,78 & 74,38 & 70,66 & 73,40 & $\overline{4,47}$ & 73,71 & 72,17 & 73,82 & 73,99 & 74,80 \\
\hline $\mathrm{TO}_{2}$ & 0,24 & 0,38 & 0,98 & 0,19 & 0,29 & 0,33 & 0,19 & 0,34 & 0,23 & 0,7 & 0,25 & 0,23 & 0,35 & 0,34 & 0,32 & 0,31 & 0,32 \\
\hline $\mathrm{Ab}_{2} \mathrm{O}_{3}$ & 13,09 & 12,69 & 14,80 & 12,74 & 11,51 & 13,04 & 12,88 & 13,80 & 13,06 & 13,68 & 12,76 & 13,09 & 13,12 & 13,9 & 13,33 & 12,57 & 13,46 \\
\hline $\mathrm{F}+\mathrm{FO}_{3}$ & 0,63 & 0,77 & 0.84 & 0.03 & 0,07 & 0,97 & 0,04 & 244 & $0 \leq 50$ & 1,06 & 0,056 & 0.29 & 0,6 & 021 & 0,64 & 0,22 & 0,07 \\
\hline$F \infty$ & 1,32 & 1,41 & 209 & 1,70 & 1,53 & 1,78 & 1,49 & 0,01 & 13 & 2,16 & 1,32 & 1,29 & 1,05 & $1, \overline{2}$ & 0.99 & 125 & 1,6 \\
\hline Mho & 0,03 & 0,03 & 35 & 0,01 & 101 & 01 & 0,01 & 0,03 & 0,03 & 0,05 & 0,03 & 0,02 & 09 & 0,0 & 100 & 0,01 & 0,01 \\
\hline Mro & 0,04 & 0,06 & 0,06 & 0,01 & 0,01 & 101 & 0,01 & 0,08 & 0,02 & 0,17 & 0,06 & 0,03 & $0, \overline{0}$ & 0,03 & 0,06 & 0,02 & 0,06 \\
\hline$C=0$ & 0,73 & 1,04 & $0,8 \mathrm{~B}$ & 038 & 0,63 & 0,69 & 0,099 & 0,35 & 0,58 & 1,29 & 058 & 0,60 & 0,97 & 0,90 & 1,07 & 0,72 & 0,72 \\
\hline NaO & 4,15 & $4 \overline{55}$ & 5,25 & $4,0,2$ & 21 & 4,17 & 4,17 & & 4,11 & 4,31 & & 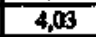 & $\sqrt[4]{42}$ & 471 & 44 & 4,64 & 4,11 \\
\hline $\bar{K}+0$ & 4,73 & 4,52 & 2 & 4,77 & 83 & 4,79 & 4,76 & 4,72 & 469 & 23 & 1 & 4,84 & 5 & 4,63 & 452 & 4,2 & 4,06 \\
\hline Ff $(9000$ & 069 & 0.96 & 0,65 & 0.51 & 04 & 0,61 & 0,53 & 099 & 0,98 & 1,62 & 080 & 0,0 & $0, \overline{61}$ & 0,56 & 0,69 & 0,94 & 0,81 \\
\hline $\mathrm{H} \mathrm{OO}^{\circ}$ & 035 & 0,23 & 31 & 031 & 34 & & 20 & & 0,15 & 0,42 & & & & 0,34 & 0,13 & 0,20 & 0,75 \\
\hline $\mathrm{P}_{2} \mathrm{O}_{3}$ & of & $0, \overline{12}$ & 10 & 0,06 & 10 & 2 & 0,07 & 0,09 & 0,08 & 0,13 & 0,09 & 0,00 & 10 & 0,12 & 0,10 & 0,11 & 0,10 \\
\hline Total & 99,81 & 99,62 & 9931 & 100,65 & 99,56 & 99,06 & 100,06 & $100, \overline{68}$ & 99,94 & 100,26 & 99,10 & 99,97 & 99,74 & 10004 & 100,14 & 99,70 & 101,03 \\
\hline En (pomin) & 750 & 780 & 2425 & $\$ 5$ & 335 & 480 & 420 & 1320 & 745 & 1115 & 710 & 735 & 760 & 700 & 700 & 525 & 945 \\
\hline $\mathbf{S} \mathbf{A}$ & d & 200 & 32 & 24 & 20 & $\mathrm{md}$ & $\mathbf{n d}$ & ad & nd & $<0$ & 20 & $M$ & od & 9 & 20 & 20 & 80 \\
\hline $\begin{array}{ll}\mathbf{L} \\
\end{array}$ & nd & $\overline{\mathrm{mi}}$ & 8 & 45 & 5 & nd & nd & nd & nd & 38 & 25 & $\overline{\mathrm{nd}}$ & nd & nd & 35 & 17 & 5 \\
\hline$s \quad$ & 90 & 125 & 140 & $<30$ & $<30$ & $<30$ & 430 & 100 & 60 & 165 & 80 & 75 & 6 & 6 & 85 & 45 & 50 \\
\hline $\mathbf{P b}$ * & 140 & 175 & 100 & 150 & 160 & $\overline{155}$ & 140 & 150 & 155 & 165 & 140 & 160 & 135 & 145 & 155 & 145 & 165 \\
\hline$Y$ & d & 20 & 37 & 42 & 37 & nd & id & $\mathbf{n d}$ & nd & 60 & 37 & nd & nd & od & 42 & 40 & 27 \\
\hline $\mathbf{z}$ & 165 & 170 & 310 & 195 & 195 & 215 & 165 & 260 & 190 & 240 & 180 & 165 & 205 & 20 & 185 & 180 & 175 \\
\hline $\mathbf{Z n} \quad$ " & 55 & 5 & 120 & 70 & 50 & 30 & 50 & 100 & 95 & 130 & $<15$ & 30 & 40 & 75 & 55 & 0 & 85 \\
\hline
\end{tabular}

al 1980 e Batchelor \& Bowden 1985), mostrando comportamento típico de rochas alcalinas pós ou anorogênicas (Fig. 6).

As características geoquímicas das amostras do Granito da Ramada consideradas nesta pesquisa indicam decisivamente sua afinidade alcalina. E, no entanto, com relação aos elementos traços que as rochas estudadas mostram-se de difícil caracterização, permitindo interpretações dúbias. Um primeiro exame dos conteúdos de elementos traços indica que não se verifica o enriquecimento em elementos de alta carga e pequeno raio, típico em muitos dos granitos da série alcalina. Assim, os teores de $\mathrm{Zr}, \mathrm{Nb}, \mathrm{Y}$ e terras raras são relativamente baixos, assemelhando-se aos observados nos granitos da série cálcio-alcalina, por exemplo. Plotadas no diagrama $(\mathrm{Y}+\mathrm{Nb}) \mathrm{X} \mathrm{Rb}$, de Pearce et al (1984), as amostras do Granito da Ramada situam-se entre o campo dos granitos de arcos magmáticos e os intraplacas. Os padrões apresentados pelas amostras estudadas nos spiderdiagrams dos mesmos autores (Fig. 7) mostram similaridade com os granitos de arco vulcânico do Chile. O critério sugerido por Whalen et al (1987) para distinguir granitos do tipo A, utilizando o somatório dos teores de $\mathrm{Zr}, \mathrm{Nb}, \mathrm{Ce}$ e $\mathrm{Y}$, não define as amostras estudadas como de granitos do tipo A.

A revisão dos dados constantes na bibliografia sobre as principais associações alcalinas supersaturadas em sílica de ambientes anorogênicos ou pós-orogênicos (Jacobson et al 1958, Liégeois \& Black 1987, Bonin 1982, Harris 1985, Sheraton \& Black 1988, Taylor et al 1980 e Anderson et al 1980) mostra que os tipos meta ou peraluminosos podem ser empobrecidos nesses elementos de alto potencial iônico, denominados HFS (high field strength) por alguns autores. Gwinn \& Hess (1989) explicam o enriquecimento dos elementos HFS nos diferenciados peralcalinos por causa de sua maior solubilidade em líquidos ricos em álcalis. No que diz respeito aos líquidos meta e peraluminosos da mesma associação alcalina, é provável que o freqüente enriquecimento em HFS esteja relacionado à evolução da fonte dos magmas alcalinos à medida que os processos orogênicos dão lugar ao magmatismo extensional anorogênico. De modo geral, o magmatismo alcalino pós-orogênico apresenta menor enriquecimento em elementos HFS que o magmatismo tipicamente alcalino anorogênico relacionado com rifles. Os padrões de elementos terras raras (Tab. 2), de amostras representativas do Granito da Ramada (Fig. 8), normalizados pelo padrão condrítico de Haskinefa et al. 1968, são similares aos descritos por Nardi( 1989) como típicos dos granitos alcalinos pós-orogênicos. Taylor et al (1980) descrevem padrões de ETR semelhantes em biotita-hastingsita granitos do Complexo ígneo de Topsails, Newfoun-dland, Canadá, constituintes de suíte alcalina pósorogênica de 


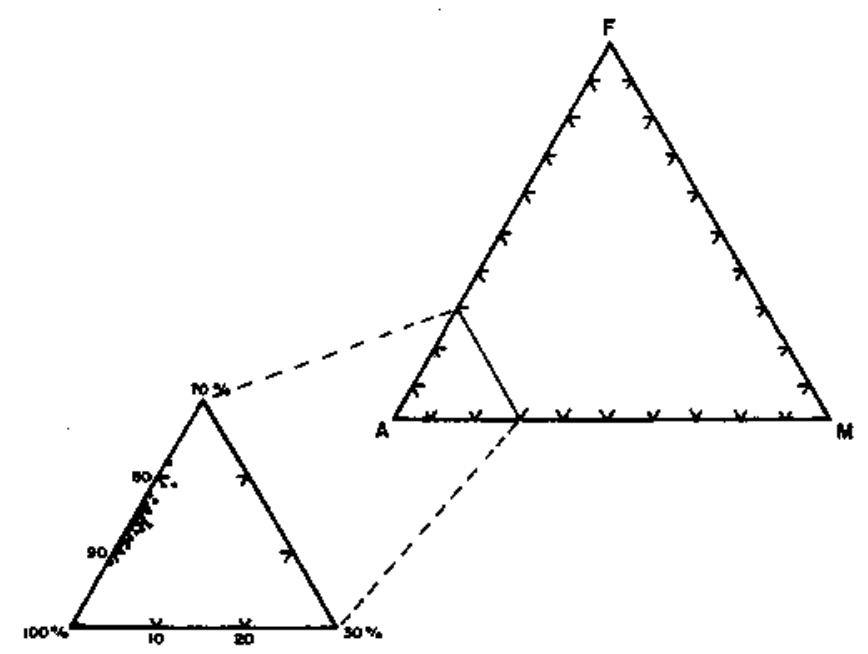

Figura 3 - Diagrama FMA (FeO $\left.\mathrm{Ftal}_{\text {tol }} \mathrm{MgO}: \mathrm{Na}_{2} \mathrm{O}+\mathrm{K}_{2} \mathrm{O}\right)$ ilustrando a distribuição de amostras representativas do Granito da Ramada

Figute 3 - Representative samples of Ramada Granite plotted in the FMA ( $\mathrm{FeO}_{\text {total }}: \mathrm{MgO}: \mathrm{Na}_{2} \mathrm{O}+\mathrm{K}_{2} \mathrm{O}$ ) diagram

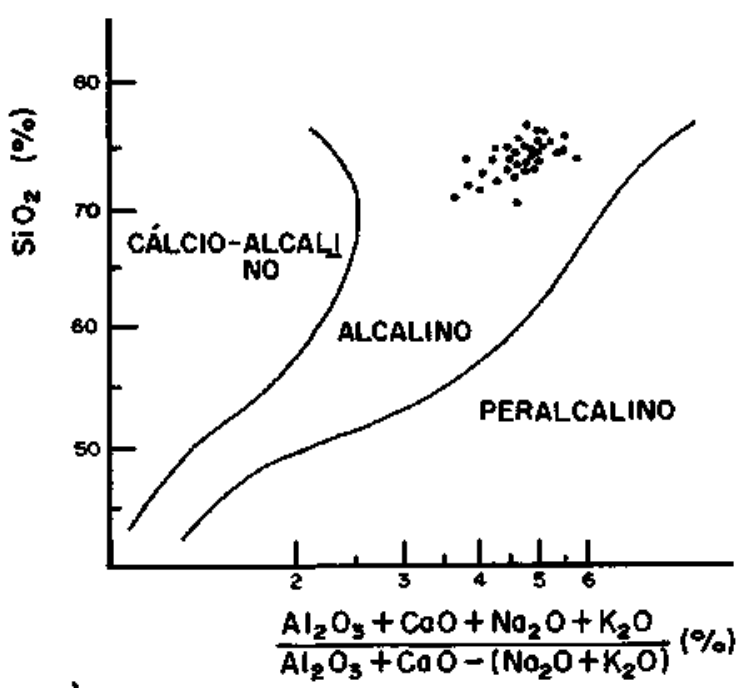

Figura 4 - Amostras representativas do Granito da Ramada colocadas no diagrama de Wright (1969)

Figure 4 - Wright (1969) diagram with Ramada Granite samples

idade do silurio-devoniana. O conteúdo absoluto de ETR no Granito da Ramada não mostra relação direta com o grau de diferenciação, sendo observável, no entanto, o aumento das anomalias negativas de Eu nos termos mais diferenciados. O padrão, fortemente empobrecido em ETR trivalente e desprovido de anomalia negativa de Eu, corresponde às porções feldspáticas de origem cumulática sugeridas pelas texturas glomeroporfíríticas.

Pelo exposto, é possível concluir que, embora a geoqurmica dos elementos traços no Granito da Ramada não seja diagnostica de sua afinidade alcalina, ela é comparável à de diversos granitos metaluminosos de associações alcalinas pós-orogênicas.

QUÍMICA MINERAL A composição química das principais fases minerais componentes do Granito da Ramada foi estudada por microssonda eletrônica nas Universidades de Paris-Sud e Pierre et Marie Curie.

Os anfibólios variam composicionalmente de magnésiohornblenda, nos termos menos diferenciados, até hornblenda ferroedenítica, nos sienogranitos (Tab. 3). Suas razões $\mathrm{FeO}(\mathrm{T}) / \mathrm{FeO}(\mathrm{T})+\mathrm{MgO}$ variam de 0,68 até 0,83 , não atingindo
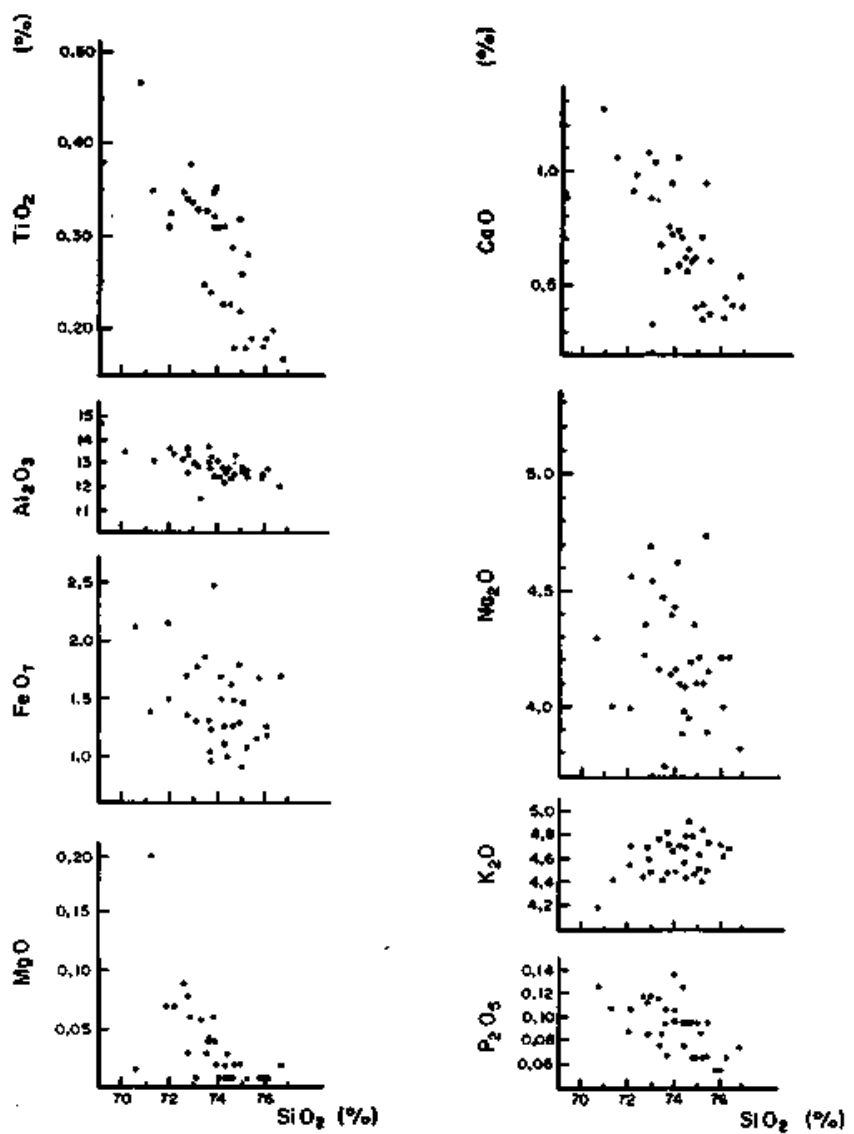

Figura 5 - Apresentação da composição de amostras representativas do Granito da Ramada, em diagramas de elemento maior $\mathrm{X} \mathrm{SiO}_{2}$ (diagramas de Harker)

Figure 5 - Diagrams of major elements versus silica (Harker diagrams) of Ramada Granite samples

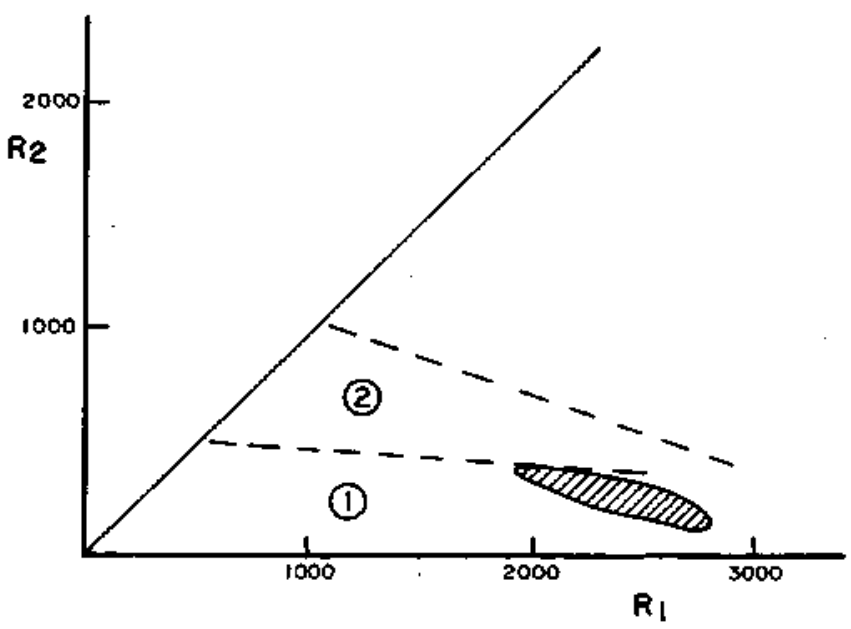

Figura 6 - Diagrama R1R2 com os campos propostos por Batchelor \& Bowden (1985) ilustrando a composição de amostras representativas do Granito da Ramada. 1. Suites anorogênicas; 2. suites tardi-orogênicas, campo assinalado - definido por amostras representativas do Granito da Ramada Figure 6 - Field of representative samples of Ramada Granite plotted in RIR2 diagram modified by Batchelor \& Bowden (1985). 1. Anorogenic suites; 2. late-orogenic suites

os valores típicos de anfibólios de rochas graníticas alcalinas acima de 0,9 (Nardi 1984). Estas baixas razões são compreendidas pela observação petrográfica da cristalização precoce 


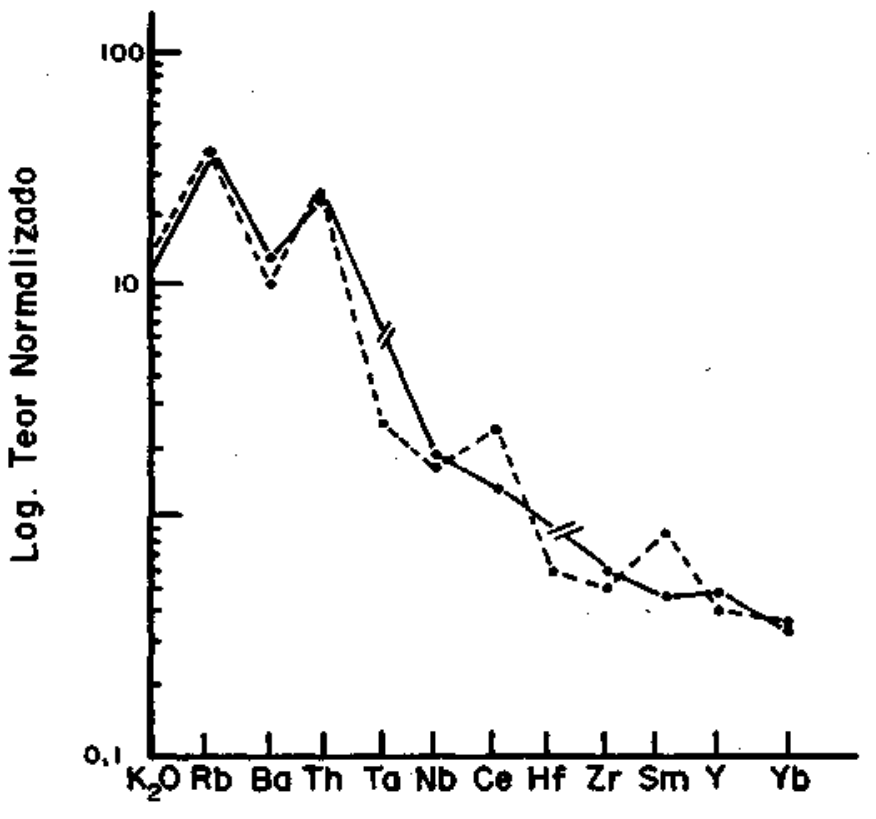

Figura 7 - Diagrama multielementar (spiderdiagram) mostrando o padrão típico de arcos estudados (Unha cheia) comparativamente com os granitos de arcos maturos do Chile, conforme Pearce et al. (1984) (linha tracejada)

Figure 7 - Spiderdiagrams for Ramada Granite samples (full lines) compared with granites of mature volcanic arc, Chile (broken lines) based on Pearce et al. (1984)

Tabela 2 - Concentrações de elementos terras raras (ETR) em amostras representativas do Granito da Ramada Table 2 - Rare Earth element concentration in Gramada Granite representative sample

\begin{tabular}{|c|c|c|c|c|c|c|c|c|}
\hline & MS5 & PM 166 & RMS9 & RM 64 & RM 112 & RM 206 & RM 260 & R44 147 \\
\hline La & 28,10 & 3050 & $50, A_{0}$ & 13,20 & 12,30 & 4,37 & 16,10 & 64,20 \\
\hline Ce & 4850 & 6530 & 86,60 & 28,40 & 200 & 6,18 & 33,10 & 131,00 \\
\hline $\mathbf{N}$ & 2590 & 2370 & 35,30 & 1430 & 990 & 238 & 16,00 & 51,80 \\
\hline $\sin$ & 490 & $48 \overline{0}$ & 650 & 270 & 230 & 056 & 320 & 1000 \\
\hline By & $.0,43$ & 0,4 & 1,20 & 0.42 & $\mathbf{0 . 1 3}$ & 0.16 & 0,36 & 0.59 \\
\hline od & 430 & 4,60 & $5, \pi$ & 2,60 & 290 & 939 & 3,10 & 890 \\
\hline Dy & 370 & 5,00 & 490 & 2,40 & 5,40 & 0,30 & 3,10 & 790 \\
\hline $\mathrm{H}_{0}$ & 968 & 0,8 & 0,85 & 0,4 & 190 & 0,08 & 0,56 & $1, n$ \\
\hline B & 2,10 & 3,20 & 270 & 152 & 360 & 02 & 250 & 4,30 \\
\hline $\mathbf{r b}$ & 230 & 350 & 270 & 1,80 & 350 & 029 & 250 & 4,20 \\
\hline $\mathbf{L}$ & 033 & 050 & 0,37 & 031 & 054 & 0,05 & 0,37 & 0,52 \\
\hline
\end{tabular}

de magnetita e ilmenita associada com os anfibólios, sugerindo Poi excessivamente elevada para líquidos de afinidade alcalina. A biotita, da mesma forma que os anfibólios, também apresentam teores de $\mathrm{MgO}$ superiores aos esperados em granitos alcalinos. As razões $\mathrm{FeO}(\mathrm{T}) / \mathrm{FeO}(\mathrm{T})+\mathrm{MgO}$ situam-se entre 0,76 e 0,81 e as biotitas normais dos granitos alcalinos mostram valores superiores à 0,85 (Anderson et al. $1980 \mathrm{e}$ Nardi 1984). A tabela 3 ilustra a composição da biotita por meio de três análises representativas. O decréscimo do conteúdo de $\mathrm{TiQ}_{2}$ da biotita correlaciona-se com o aumento da proporção $\mathrm{Fe} / \mathrm{Mg}$ e com o grau de diferenciação da rocha hospedeira.

O plagioclásio tem conteúdo de anortita variável, constituindo desde albita pura até oligoclásio com $\mathrm{An}_{20}$ Análises representativas dos feldspatos estão na tabela 3.

Os minerais opacos estudados no Granito da Ramada são magnetita e ilmenita, cujas composições médias estão representadas na tabela 3 . Os baixos conteúdos de $\mathrm{TiO}_{2}$ da magnetita associado ao igualmente baixo teor de $\mathrm{Fe}_{2} \mathrm{O}_{3}$ da ilmenita

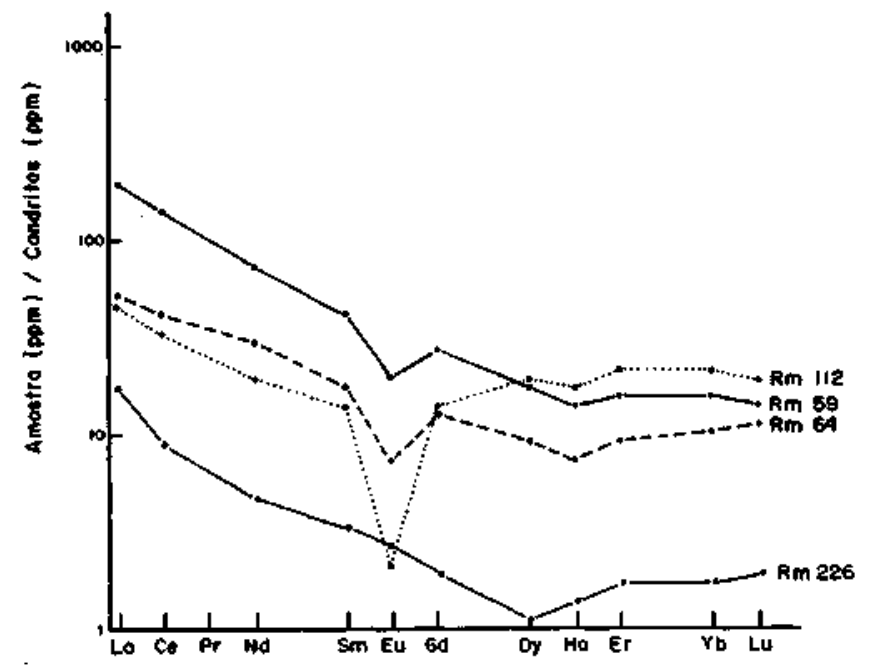

Figura 8 - Padrões normalizados de ETR representativos das variações observadas no Granito da Ramada. Normalização pelos valores condríticos de Haskin et al. (1968)

Figure 8 - REE patterns of Ramada Granite representative samples, normalised against chondritic values of Haskin et al. (1968)

ihnenita sugere que estas fases foram reequilibradas abaixo de $650^{\circ} \mathrm{C}$ e a Poz inferior a IO" ${ }^{\prime 18}$ aim. O conteúdo de MnO é baixo na magnetita, mostrando correlação positiva com o teor de TCCfe. A ilmenita apresenta conteúdo relativamente elevado de $\mathrm{MnO}$.

Tabela 3 - Composição química de fases minerais representativas do Granito da Ramada. $\mathrm{FeO}^{*}$ e $\mathrm{Fe}_{2} \mathrm{O}_{3} *=$ valores calculados, $A N F=$ anfibólios, $B I O-$ biotita, $P L G=$ plagioclásio, $M A G=$ magnetita, ILM - ilmenita. Resultados obtidos por microssonda eletrônica

Table 3 - Chemical composition of representative mineral phases, of Ramada Granite. $\mathrm{FeO}^{*}$ and $\mathrm{Fe}_{2} \mathrm{Q}$ ) $*$ calculated values, $\mathrm{ANF}=$ anphiboles, $\mathrm{BIO}$ biotites, $\mathrm{PLG}=$ plagioclase, $\mathrm{MAG}=$ magnetite, $\mathrm{ILM}=$ ilmenite. Results obtained by microprobe

\begin{tabular}{|c|c|c|c|c|c|c|}
\hline & ANFO 1 & ANF⿻ & ANIF3 & Bio01 & Bion & Biono \\
\hline $\mathrm{SiO}_{2}$ & 4295 & 46,01 & 44,17 & 36,12 & 36,13 & 35,09 \\
\hline $\mathrm{TO}_{2}$ & 123 & 125 & 126 & 488 & 458 & 279 \\
\hline $\mathrm{Al}_{4} \mathrm{O}_{3}$ & 7,84 & 6,42 & 6.26 & 12,92 & 2,26 & 1279 \\
\hline FoOt( & 26,52 & 20,65 & 21,83 & 26,46 & 25,49 & 28,25 \\
\hline $\mathrm{MrO}$ & 0,91 & 0,64 & 0,72 & 09 & 0,61 & 072 \\
\hline Mro & 5,46 & 9,61 & 8,69 & 830 & 739 & 671 \\
\hline co & $10, \overline{66}$ & 10,47 & 10,03 & 0,01 & 0,01 & 020 \\
\hline $\mathrm{N}_{a_{7} \mathrm{O}} \mathrm{O}$ & 2,08 & 1,39 & 2,09 & 0,25 & 0,26 & 0,12 \\
\hline $\mathrm{K} \times 0$ & 1,27 & 0,46 & 0,84 & 9,38 & 9,04 & 8,72 \\
\hline \multirow[t]{2}{*}{ Total } & 9899 & 96,84 & 959 & 98,70 & 95,76 & 95,39 \\
\hline & FLOOI & FLO02 & MACO1 & IMLO1 & ILAOB & \\
\hline $\mathbf{S i O}_{2}$ & 64,17 & 67,37 & 0,14 & 0.12 & 246 & \\
\hline $\mathrm{TO}_{2}$ & $=$ & $=$ & 5,47 & 48,21 & 49,60 & \\
\hline $\mathrm{Al}_{4} \mathrm{O}_{3}$ & 2,79 & 20,87 & 0,38 & - & 0,03 & \\
\hline $\mathrm{F} \in \mathrm{O}(0)$ & 0,25 & 0,52 & & & & \\
\hline$F \in 0^{\circ}$ & - & - & 35,80 & 37,17 & $41, A S$ & \\
\hline$F+0_{3}^{*}$ & $=$ & - & 58,41 & 6,92 & 0,65 & \\
\hline Mno & - & $=$ & 0,95 & 6,18 & 6,06 & \\
\hline Mro & 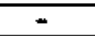 & - & $=$ & I & - & \\
\hline 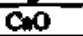 & $4, \overline{10}$ & 0,74 & $=$ & - & - & \\
\hline Nox 0 & 925 & 11,10 & $=$ & $=$ & $=$ & \\
\hline$\overline{\mathrm{KO}}$ & 0,12 & 0,15 & $=$ & 7 & $=$ & \\
\hline Totil & 10098 & 100,75 & IOE,15 & 9,60 & $100, \overline{5}$ & \\
\hline
\end{tabular}

As características composicionais das fases ferromagnesianas do Granito da Ramada não são típicas de minerais de granitos da associação alcalina. Anderson et al (1980) repor- 
taram comportamento similar dos granitos metaluminosos alcalinos do Proterozóico Médio de Wisconsin, EUA. Assim, como no Granito da Ramada, embora a proporção Fe/Mg seja alta na tocha total, os máfícos são relativamente magnesianos. Aqueles autores também atribuem tal comportamento à cristalização precoce de magnetita, indicando $\mathrm{Po}_{2}$ maior do que o usual em granitos da série alcalina.

GEOCRONOLOGIA Naime (1987), utilizando sete amostras de monzogranitos do Granito da Ramada, obteve idade $\mathrm{Rb}$-Sr de 463,5 \pm 12 Ma para razão inicial de 0,710 (Fig. 9). Embora a utilização destes dados deva considerar que o corpo granítico está nitidamente afetado por processos posteriores de hidrotermalismo, eles são sugestivos do caráter pós-orogênico do Granito da Ramada e de origem envolvendo fusão de rochas crustais relativamente enriquecidas em $\mathrm{Rb}$.

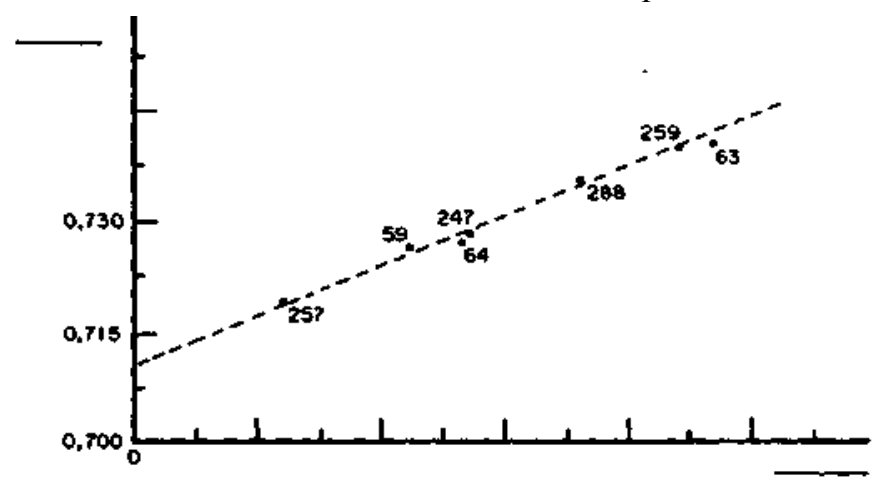

$\mathrm{Sr}$

Sr 86

0,745

\begin{tabular}{llllllll}
1 & 2 & 3 & 4 & 5 & $\mathbf{R}$ & $\mathbf{b}$ & $\mathbf{8} \quad \mathbf{7}$ \\
\hline & &
\end{tabular}

Figura 9 - Isócrona dos monzogranitos do Granito da Ramada (Naime 1978). Razão inicial - 0,71082 $\pm 0,00044$ $(0,06 \%)$, idade para $1,42 E-5=463 \pm 12,5 \mathrm{Ma}, M S W D=$ $2,343006 \mathrm{~T} \mathrm{i}=7$

Figure 9 - Isochome of Ramada monzogranites (Naime 1988). Initial ratio $=0,71082+0,00044(0,06 \%$, age for $1.42 \mathrm{E}-5=462 \pm 12.5 \mathrm{Ma}$, MSWD $=2.343006 \mathrm{~N}-7$

A idade obtida para o Granito da Ramada é similar à obtida nos microgranitos alcalinos do Complexo Granítico São Sepé (Sarton 1978) e nos riolitos alcalinos do Cerro Tupanci referidos por Soliani (1986). De acordo com os dados disponíveis no presente, o Granito da Ramada constitui uma das mais jovens manifestações de magmatismo alcalino pós-Brasiliano que parece ter iniciado com os magmas geradores dos pertita granitos de Lavras do Sul e talvez do Sienito Piquiri, cujas idades são estimadas em torno de 550 Ma (Soliani 1986).

CONSIDERAÇ̃̃ES PETROGENÉTICAS O Granito da Ramada apresenta características gerais que permitem incluí-lo entre os granitos da associação alcalina supersaturada em silica. Nardi \& Bonin (1991) incluiram-no na Suíte Intrusiva Saibro, constituída pelos granitos peralcalinos da região de Dom Pedrito (Hartmann \& Nardi 1982), pelos pertita granitos do Complexo Granítico de Lavras do Sul (Nardi 1984), pelo Granito Jaguari, por corpos sieníticos da região de Dom Pedrito-Lavras do Sul (M. C. Gastai, comunicação verbal) e, provavelmente, pelo Sienito Piquiri (Jost et al 1984) e grande parte do Complexo Granítico São Sepé (Sartori 1978), entre outros. Estas rochas apresentam idades radiométricas (principalmente Rb-Sr) entre 570 e 450 Ma (Soliani 1986), demarcando o magmatismo associado ao período de estabilização dos terrenos afetados pela oroçênese brasiliana. A exemplo de diversas outras situações similares (Tauson \& Kozlov 1972, Whalen et al 1987), esta suíte é tipicamente pós-orogênica e inclui desde granitos e sienitos claramente alcalinos até tipos metaluminosos de difícil caracterização, como é o caso do estudado neste artigo.

A gênese dos magmas alcalinos supersaturados em silica tem sido atribuída pela maioria dos autores à fusão parcial da crosta inferior relativamente anidra (Collins et al1982, Whalen et al (1987) ou à diferenciação de magmas dominantemente mantélicos (Brown 1981, Bonin 1982, Upton \& Emeleus 1987, ). A razão $\mathrm{Sr}^{87} / \mathrm{Sr}^{86}$ inicial do Granito da Ramada próxima de 0,710 , ao lado de suas características petrológicas e geoqumiicas, é compatível com a fusão parcial, talvez de rochas granulíticas quartzofeldspáticas do Complexo Granulítico de Santa Maria Chico (Nardi \& Hartmann 1979), ou mesmo de rochas graníticas mais precoces como preconizado por Bonin et al (1987). É importante, no entanto, ressaltar que cálculos de balanço de massas indicam que a composição química dos líquidos correspondentes ao Granitoda Ramada poderia ser derivada de magmas traquíticos composicionalmente similares aos sienitos da região de Dom Pedrito-Lavras do Sul. De acordo com estes cálculos, baseados em programa desenvolvido por Baker et al (1985), este líquido granítico poderia representar $36 \%$ de fusão remanescente após o fracionamento da seguinte composição: $80 \%$ defeldspato alcalino $(47 \%$ Or $+53 \%$ Ab) $+3,60 \%$ magnetita + $2,10 \%$ ilmenita $+0,66 \%$ apatita $+14 \%$ de clinopiroxénio, resultando em cumulado sienítico.

Os magmas que originaram o Granito da Ramada eram ricos em água, como sugere a cristalização de anfibólio precoce, sua cristalização subsolvus e a existência de cavidades miarolíticas. A quantidade de $\mathrm{H}_{2} \mathrm{O}$ pode ser de aproximadamente $4 \%$, com base na cristalização precoce de anfibólio. Estes magmas apresentavam Poa relativamente elevada para líquidos alcalinos, resultando na cristalização precoce de óxidos de ferro e titânio, simultânea com a de anfibólios cálcicos. Com base nestes parâmetros e sendo admitida a temperatura de $900^{\circ} \mathrm{C}$ a viscosidade deste magma seria relativamente baixa $\left(10^{6}\right.$ poises) antes da cristalização ter início. $\mathrm{O}$ posicionamento desta intrusão em níveis rasos da crosta, epizona, é coerente com estas deduções teóricas.

A diferenciação observada entre as diversas fácies do Granito da Ramada é resultante de diversos processos: fracionamento de feldspatos, gerando texturas cumuláticas localizadas; fracionamento localizado de fases acessórias como apatita+titanita+óxidos de ferro e titânio, ocasionando provavelmente os trends geoquunicos paralelizados para $\mathrm{HQz}$ e $\mathrm{P}_{2} \mathrm{O}_{5}$ principalmente, nos diagramas de Harker. Como terceiro processo, mas talvez o de maior importância, Naime (1987) sugere a atuação de mecanismos do tipo termodifusão no estado líquido (Hildreth 1981) com base na acentuada variação ao longo da diferenciação no conteúdo de alguns elementos traços. $\mathrm{O}$ fracionamento de uma assembléia dominada por anfibólio e feldspatos, durante a ascenção e posicionamento das prováveis injeções que geraram o Granito da Ramada, seguida de fracionamentos localizados de fases acessórias, à exemplo do preconizado por Nardi \& Bitencourt (1989) para granitos leucocraticos muito diferenciados, pode explicar a maioria das feições observadas no granito. Para isso, é necessário que sejam admitidos altos coeficientes de partição, como os descritos por Mahood \& Hildreth (1983) e Nash \& Crecraf (1985) para líquidos com altos conteúdos de silica.

A cristalização dos magmas geradores do Granito da Ramada foi iniciada com a formação de hornblenda magnesiana + óxidos de ferro e titânio + zircão, evoluindo para a cristalização de plagioclásio + apatita além dos já mencionados, e posteriormente quartzo + biotita + feldspato alcalino. A cristalização do quartzo, na realidade, iniciou-se antes da maior parte do feldspato alcalino, como é freqüente nos granitos da série alcalina, devido à elevada atividade da sflica. Após a consolidação deste corpo granítico, fluidos hidrotermais provocaram transformações mineralógicas significativas, como o avermelhamento dos feldspatos, propilitização e sericitização associada à formação de sutfetos e carbonates. 
CONSIDERAÇÕES FINAIS O Granito da Ramada apresenta características gerais que permitem inclui-lo na associação alcalina pós-orogênica, descrita no Rio Grande do Sul como Suíte Intrusiva Saibro (Hartmam \& Nardi 1982, Nardi \& Bonin 1991). A designação de associação alcalina, em detrimento de série alcalina, é tida como preferível, já que líquidos graníticos gerados por fusão crustal podem integrar este conjunto. As rochas estudadas exemplificam um tipo de granito de ocorrência freqüente nas associações alcalinas, que exibe no entanto diversas características similares às de granitos cálcio-alcalinos muito diferenciados. Juntamente com Whalen et al (1987) e Bonin (1982), conclui-se pela importância de estudar as rochas em conjunto com os demais tipos litológicos associados. Em muitos casos, o critério que permite classificar um determinado corpo granítico é exclusivamente por enquadramento em um conjunto litológico com características passíveis de identificação.

O Granito da Ramada mostra conteúdos de elementos maiores indicativos de sua af iliação com a associação alcalina, destacando-se o índice agpaítico, sua posição no diagrama $\mathrm{R} 1 \mathrm{R} 2$ e a proporção $\mathrm{Fe} / \mathrm{Mg}$ na rocha total. Dentre os elementos traços estudados, apenas os elementos terras raras são sugestivos de sua afinidade alcalina. Os dados de química mineral refletem uma cristalização sob condições excepcionalmente oxidantes, não sendo também indicativos de sua afinidade alcalina.

Embora o granito estudado não tenha sido avaliado do ponto de vista metalogenético, são significativos os seguintes aspectos: nas associações alcalinas, a maior parte das mineralizações está nos granites portadores de biotita. Isto é, nos metaluminosos, o caráter suhso/vus de sua cristalização, bem como a existência de cavidades miarolíticas indicam abundância de fluídos no magma granítico; a intrusão mostra fortes transformações hidrotermais e parte de suas encaixantes são relativamente reativas e ricas em água. De acordo com os critérios gerais de potencialidade metalogenética (Plant et al 1983), o Granito da Ramada apresenta significativa probabilidade de estar associado a depósitos minerais.

Agradecimentos Este trabalho f oi financiado com recursos do Conselho Nacional de Desenvolvimento Científico e Tecnológico $(\mathrm{CNPq})$ e da Financiadora de Estudo e Projetos (FINEP). A CAPES proporcionou os estudos de química mineral junto à Universidade de Paris pelo segundo autor. Incluímos nossos agradecimentos aos revisores da RBG pela considerável melhoria do texto.

\section{REFERÊNCIAS BIBUOGRÁRCAS}

ANDERSON, JX; CULLERS, R.L.; Van SCHMUS, W R. 1980. Anorogenic Metaluminous and Peraluminous Granite Plutonism in the MidProterozoic of Wisconsin, USA. Contrib. Mineral Petrol, 74:311-328.

BAKER, B.H.; McBIRNEY, A.R.; GEIST, D.J. 1985. GPP - A program package for creating and using geochemical data files. Eugene, Center for Volcanology/Univ. Oregon.

BONIN, B. 1982. Les Granites des Complexes Annulaires. BRGM. 182 p. (Manuels et methodes 4)

BONIN, B. 1988. Perakaline granites in Corsica: some petrological and geochemical constraints. Rend. Soe. Italiana Mineral. Petrol. 43(2):281-306.

BONIN, B.; PLATEVOET, B.; VIALETTE, Y. 1987. The geodynamic significance of alkaline magmatism in the Western Mediterranean compared with West Africa. Geol. J., 22:361-387.

BROWN, G.C. 1981. Space and time in granite plutonism. Phil. Trans. $R$ Soc. London., A301:321-336.

COLLINS, W.J.; BEAMS, S.D.; WHITE, A.J.; CHAPPELL, B.W. 1982 Nature and origin of A-type granites with particular reference to southeastern Austrália. Contrib. Mineral. Petrol., 80:189-200.

DEBON, F. \& LE FORT, P. 1983. A chemical-mineralogical classification of common plutonic rocks and associations. Trans. Roy. Soc. Edinburg. 73:135-149.

DE LA ROCHE, H.; LETERRIER, J.; GRANCLAUDO, P.; MARCHAL, M. 1980. A classification of volcanic and plutonic rocks using RI R2 diagrama and major element analyses. Its relationships with current nomenclature. Chem Geol, 29:183-210.

EWART, A. 1979. A review of the mineraloy and chemistry of Tertiary-Recent dacitic, latitic, rhyolitic, and related salic volcanic rocks. In: BARKER, F. ed. Trondhjemites, Dacites and Related Rocks. Elsevier, Oxford p. $13-121$.

GWINN, R. \& HESS, P.C. 1989. Iron and titanium solution properties in peraluminous and peralkaline rhyolitic liquids. Contrib. Mineral. Petrol., 101:326-338.

HARRIS, N.B.W. 1985. Alkaline complexes from the Arabian Shield. $J$. African Earth Sciences., 3:325-337.

HARTMANN, L.A. \& NARDI, L.V.S. 1982. Os Granites Santo Afonso, Saibro e Vauthier da região do Arroio Santa Maria Chico, Dom Pedrito, RS. Ácta Geol Leopold.., VI: 153-178.

HASKIN, LA.; HASKIN, M.A.; FREY, FA. 1986. Relative and absolute terrestrial abundances of the rare earths. In: AHRENS, L.H. ed. Origin and Distribution of the Elements. Oxford, Pergamon. p. 889-912.

HILDRETH, W. 1981. Gradient in silicic magma chambers: implications for lithospheric magmatism. J. Geophys. Res., 86:10153-10192.

JACOBSON, R.; McLEOD, W.N.; BLACK, R. 1985. Ring complexes in the younger granite province of Northern Nigeria. Geol. Soc. London Mem., (1):72 p.

JOST, H.; BROD, J.A.; HOLZ, M.; KUHN, A.; FLOR, MA.; KRONBAUER, A.; DILLENBURG, S. 1985. Geologia estrutural, petrografia e petrologia do Sienito Piquiri (Proterozoico Superior), Rio Grande do Sul. In: SIMP. SUL-BRAS. GEOL., 2. Florianópolis, 1985. Anais... Florianópolis, SBG. v. 1, p. 63-81.

LEINZ, V.; BARBOSA, A.F.; TEIXEIRA, E. 1941. Mapa Geológico Caçapava-Lavras. Porto Alegre, Secr. Agr. Ind. Com. 39 p. (Boletim).

LIÉGEOIS, J.P. \& BLACK, R. 1987. Alkaline magmatism subsequent to collision in the Pan-African belt of the Adrar des Iforas (Mali). In:
FITTON, J.G. \& UPTON, B.G.J. eds. Alkaline Igneous Rocks. Geol Soc. $n^{\circ} 30$, p. 381-401. (Spec. Publ.).

MAHOOD, G. \& HILDRETH, W. 1983. Large partition coefficients for traces elements in high-silica rhyelites. Geochim. Cosmochim. Acta., 47:11-30.

MARTIN, R.F. \& PIWINSKH, A.J. 1972. Magmatism and tectonic setting. J. Geophys. Res., 70:3485-3496.

MOREIRA, M.L. \& MARIMON, M.P. 1982. Estudo petrográfico e litoquímico das rochas graníticas do escudo Sul-Rio-grandense. In: CONOR. BRAS. GEOL., 32. Salvador, 1982. Anais... Salvador, SBG. v.2, p. 556-576.

NAIME, R.H. 1987. Geologia, Geoquímica e Petrologia do Complexo Granitico Ramada e do Granito Cerro da Cria. Porto Alegre. 148 p. (Dissertação Mestrado, UFRGS).

NARDI, L.V.S. 1984. Geochemistry and Petrology of the Lavras Granite Complex, RS, Brasil England. 268 p. (PhD thesis, London University).

NARDI, L.V.S. 1989. Geoquímica dos elementos terras raras nas rochas graníticas da região centro-sul do Brasil. In: FORMOSO, M.L.L.; HARTMANN, LA.; NARDI, L.V.S. eds. Geoquímica dos Elementos Terras Raras no Brasil Porto Alegre, DNPM/CPRM. p. 71-82.

NARDI, L.V.S. \& BITENCOURT, MF. 1989. Geologia, petrologia e geoquímica do Complexo Granítico de Caçapava do Sul, RS. Rev. Bras. Geoc., 19:153-169.

NARDI, L.V.S. \& BONIN, B. 1991. Post-orogenic andnon-orogenic alkaline granites associations: the Saibro Intrusive Suite, Southern Brazil. A case study. Chem. Geol, (Submetido em 03/90).

NARDI, L. V.S. \& HARTMANN, L. 1979.0 complexo granulítico Santa Maria Chico do Escudo Sul-rio-grandense.Acta. Geol Leopold.,3(6):45-15.

NASH, W.P. \& CRECRAFT, H.R. 1985. Partition coefficients for trace elements in silicic magmas. Geochim. Cosmochim. Acta., 49:2309-2322.

NEARY, C; GASS, L; CAVANAGH, B. 1976. Granitic Association of Northeastern Sudan. Bull Geol Soc. América., 87:1501-1512.

PEARCE, J.A.; HARRIS, N.B.; TINDLE, A.G. 1984. Trace element discrimination diagrams for the tectonic interpretation of granitic rocks. J. Petrol., 25:956-983.

PLANT, JA.; SIMPSON, PJL; GREEN, P.M; WATSON, J.V.; FOWLER, M.B. 1983. Metalliferous and mineralized Caledonian granites in relation to regional metamorphism and fracture systems in northern Scotland. Trans. Inst. Min. Metall, 92(B):33-42.

RIBEIRO, M.1983. Informes sobre a Formação Maricá. Iheringia, 9:1-84. (Série Geologia)

RIBEIRO, M.; BOCCffl, P.R.; FIGUEIREDO, F.P.M.; TESSARI, RJ. 1966. Geologia da Quadrícula de Caçapava do Sul RS. Rio de Janeiro, DNPM/DFPM 232 p. (Boletim 127).

ROGERS, J.J. \& GREENBERG, JJC. 1981. Trace-elements in continentalmargin magmatism: Part ID. Alkali granites and their relationship to cratonization. Geol. Soc. Am. Bull, 92(1):6-9. (Part I).

SARTORI, P.L. 1978. Petrologia do Complexo Granítico São Sepé, RS. São Paulo. 196 p. (Tese de Doutorado, IG/USP).

SHERATON, J.W. \& BLACK, L.P. 1988. Chemical evolution of granitic rocks in the Eastern Antartic Shield, with particular reference to post-orogenic granites. Uthos, 21:37-52.

SOLIANI, E., Jr. 1986. Os Dados Geocronológicos do Escudo Sul-Rio-Grandense e suas Implicações de Ordem Geotectônica. São Paulo. 239 p. (Tese de Doutorado, IG/USP). 
SULTAN, M.; BATIZA, R.; STURCfflO, N.C. 1986. The origin of smallscale geochemical and mineralogic variations in a granite intrusion: A crystallization and mixing model. Contrib. Mineral. Petrol, 93:513523.

SYLVESTER, P.J. 1989. Post-collisional alkaline granites. J. Geol, 97:261280.

TAUSON, L.V. \& KOZLOV, V.D. 1972. Distribution function and ratios of trace element concentrations as estimators of the ore-bearing capacity potential granites, ID: Geochemical Exploration 1972. Inst. Min. Metall., p.37-44.

TAYLOR, R.P.; STRONG, D.F.; KEAN, B.F. 1980. The Topsails Igneous Complex: Silurian-Devonian peralkaline magmatism in western Newfoundland. Can. J. Earth Scl, 17:425-439.

UPTON, B.G.J. \& EMELEUS, C.H. 1987. Mid-Proterozoic alkaline magmatism in southwestern Greenland: The Gardar Province. In: FTTTON, J.C. \& UPTON, B.GJ. eds. Alkaline Igneous Rocks. Geol. Soc. p. 449-471. (Spec. Publ. 30).

WHALEN, J.B. \& CURRIE, K.L. 1984. The Topsails Igneous Terrane, Western Newfoundland: evidence for magma mixing. Contrib. Mineral. Petrol., 87:319-327.
WHALEN, J.B.; CURRffi, K.L.; CHAPPELL, B.W. 1987. A-type granites geochemical characteristics, discrimination and petrogenesis. Contrib. Mineral Petrol, 95:407-419.

WRIGHT, J.B. 1969. A simple alkalinity ratio and its application to questions of non-orogenic granite genesis. Geol. Mag., 106:370-384.
MANUSCRITO A670

Recebido em 2 de agosto de 1990 Revisão do autor em 20 de fevereiro de 1991 Revisão aceita em 28 de fevereiro de 1991 